九州大学学術情報リポジトリ

Kyushu University Institutional Repository

\title{
A Derivation of the Associated Flow Rule
}

Hashiguchi, Koichi

Laboratory of Agricultural Machinery, Faculty of Agriculture, Kyushu University

https://doi.org/10.5109/23697

出版情報: 九州大学大学院農学研究院紀要. 24 (2/3)，pp.75-80，1979-11. Kyushu University バージョン：

権利関係 : 


\title{
A Derivation of the Associated Flow Rule
}

\author{
Koichi Hashiguchi \\ Laboratory of Agricultural Machinery, Faculty of Agriculture, \\ Kyushu University 46-05, Fukuoka 812
}

(Received May 29, 1979)

\begin{abstract}
The associated flow rule in the traditional theory of plasticity has been recently adopted even in the plastic constitutive equations with the elastic-plastic transition. The proofs of this rule in the past, however, are confined to the classical idealization of elastoplastic continuum to ignore the elastic-plastic transition and the alteration in an elastic response. In this paper, based on two physically plausible assumptions, the associated flow rule is analytically derived for the generalized elastoplastic continum with the elastic-plastic transition, the hardening, the perfectly-plastic and the softening behaviors and the alteration in an elastic response.
\end{abstract}

\section{INTRODUCTION}

Various constitutive equations describing a gradual transition from the elastic to the fully-plastic (yield) state (abbreviated as an elastic-plastic transition) have been proposed along the line of the traditional theory of plasticity whose constitutive equation involves inherently a yield function (e.g. Mróz, 1967; Phillips and Sierakowski, 1965; Eisenberg and Phillips, 1971; Krieg, 1975 ; Dafalias and Popov, 1975; Hashiguchi, 1978, 1979 a, b). All these equations are premised on the so-called associated flow rule. Nothing, however, was mentioned as to whether or not this rule is applicable to such a material behavior without a physical contradiction. Formerly, Drucker (1951) advocated the applicability of this rule to hardening materials on the basis of the hypothesis concerning the net work done by an external agency during a closed stress cycle. And later Palmer, et al. (1967) persisted that this rule holds for wide classes of materials exhibiting not only the hardening but the perfectly-plastic and the softening behaviors, provided that the postulate of stability in the large (cf. Drucker, 1964) can reduce to the principle of maximum plastic work. This principle, however, holds only in the classical idealization of elastoplastic continuum to ignore the elastic-plastic transition and the alteration in an elastic response. On the other hand, based on the hypothesis concerning the work done during a closed strain cycle which is less restrictive than the Drucker's hypothesis, II'ushin (1961) has concluded that this rule holds but for the alteration in an elastic response, while a linear relation between the stress and the elastic strain is assumed in his analysis. Recently, Naghdi and Trapp (1975 a, b), adopting the finite deformation theory by Green and Naghdi (1965), have elaborated the II'ushin's approach and have obtained the 
similar conclusion for the case of a linear relation between the stress rate and the elastic strain rate. The elastic-plastic transition, however, is ignored in these analyses. Against the above approaches, referring to the earlier alternate approach by Prager (1949) in which any closed cycle of stress or strain is not explicitly introduced, Phillips and Sierakowski (1965) have asserted the applicability of the associated flow rule even to an intermediate loading surface assumed by themselves. But the Prager's approach is confined to hardening materials satisfying the uniqueness condition (cf. Prager, 1949) which may correspond to the postulate of stability in the small by Drucker (1964). In this paper, based on physically plausible assumptions which can be regarded as extensions of the Prager's conditions of uniqueness and continuity, the associated flow rule is derived for the generalized elastoplastic continuum with the elastic-plastic transition and the hardening, the perfectly-plastic and the softening behaviors.

\section{A DERIVATION OF THE ASSOCIATED FLOW RULE}

Preliminarily consider the uniaxial loading of a bar. Observing the stressstrain curves schematically illustrated in Fig. 1, we could assume that in a

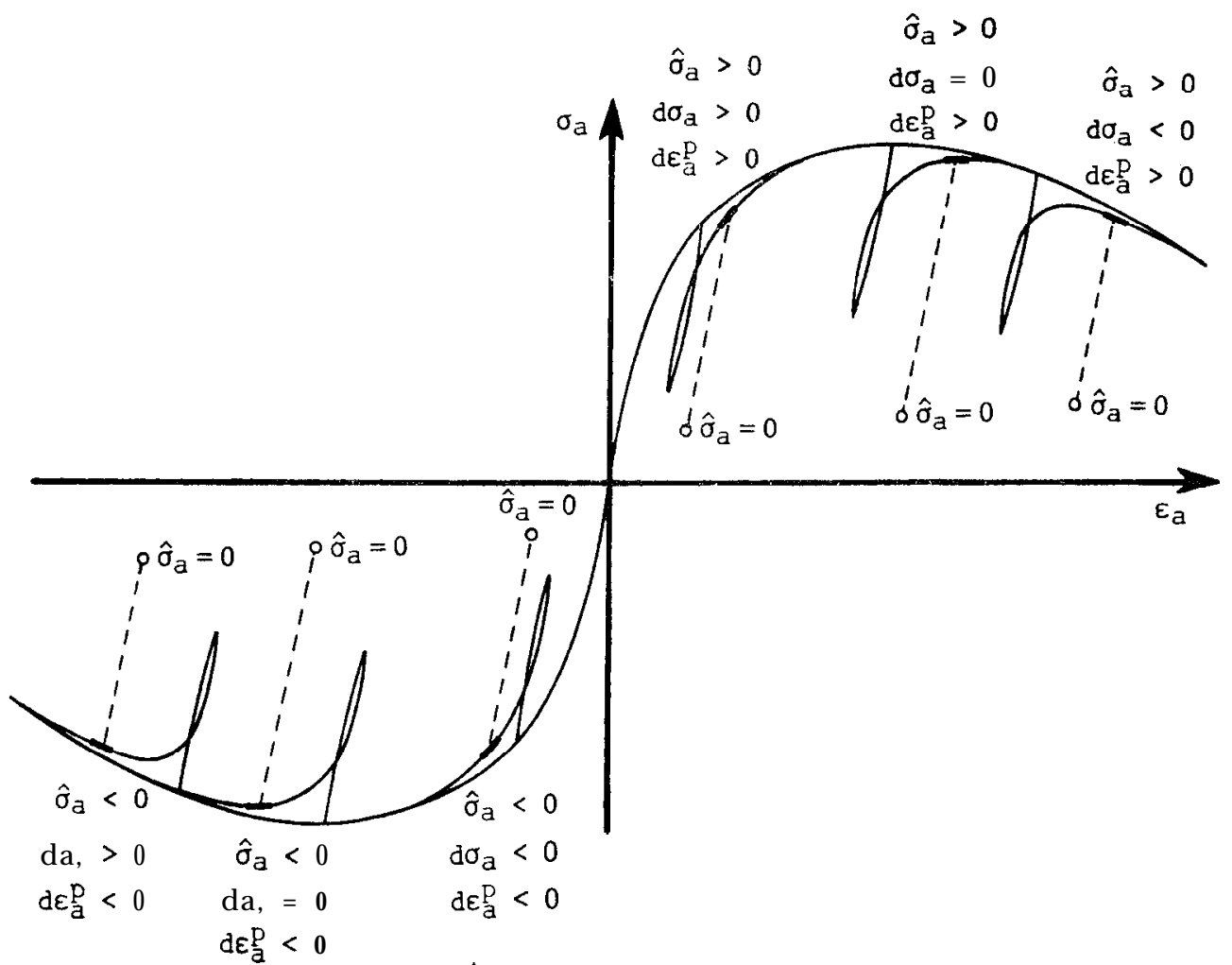

Fig. 1. Signs of $\hat{\sigma_{a}}, d \sigma_{a}$ and $d \varepsilon_{a}^{b}$ in the uniaxial loading, 
loading state

$$
\begin{aligned}
& \hat{\sigma_{a}} d \sigma_{a}>0: d \sigma_{a} d \varepsilon_{a}^{p}>0, \\
& \hat{\sigma}_{a} d \sigma_{a}=0: d \sigma_{a} d \varepsilon_{a}^{p}=0, \\
& \hat{\sigma}_{a} d \sigma_{a}<0: d \sigma_{a} d \varepsilon_{a}^{p}<0,
\end{aligned}
$$

and

$$
d \sigma_{a} \rightarrow 0 \text { as } d \varepsilon_{a}^{p} \rightarrow 0,
$$

where

$$
\hat{\sigma}_{a} \equiv \sigma_{a}-\alpha_{a} .
$$

$\sigma_{a}, \alpha_{a}$ and $\varepsilon_{a}^{b}$ are the normal components of the stress, the translation of loading surface and the strain along the axis respectively.

By extending the above notions to the general loading state, we introduce the following assumptions 1 and 2 from (1) and (2) respectively, in which the nine-dimensional stress space with superposed coordinates of stress components $\sigma_{i j}$ and plastic strain increment components $d \varepsilon_{i j}^{b}$ is introduced.

Assumption 1. When, accompanying a plastic deformation (loading state), the state of stress moves to the exterior, the tangency and the interior of the existing loading sur. face in a stress space, the plastic work done by the stress increment is positive, zero and negative respectively.

Assumption 2. As the plastic strain increment vanishes, the normal component of stress increment to the loading surface also vanishes.

Assumption 1 can be written in analytical forms as follows.

$$
\begin{aligned}
& \operatorname{tr}\left(\frac{\partial f}{\partial \boldsymbol{\alpha}} d \sigma\right)>0: \operatorname{tr}\left(d \boldsymbol{\sigma} d \boldsymbol{\varepsilon}^{p}\right)>0, \\
& \operatorname{tr}\left(\frac{\partial f}{\partial \hat{\boldsymbol{\alpha}}} d \sigma\right)=0: \operatorname{tr}\left(d \sigma d \boldsymbol{\varepsilon}^{p}\right)=0, \\
& \operatorname{tr}\left(\frac{\partial f}{\partial \boldsymbol{\alpha}} d \sigma\right)<0: \operatorname{tr}\left(d \sigma d \varepsilon^{p}\right)<0
\end{aligned}
$$

in the loading state, from which we obtain

$$
\operatorname{tr}\left(d \boldsymbol{\sigma} d \boldsymbol{\varepsilon}^{p}\right)=\operatorname{Str}\left(\frac{\partial f}{\partial \hat{\boldsymbol{\sigma}}} d \boldsymbol{\sigma}\right)(S>0),
$$

where the second-order tensors $\boldsymbol{\sigma}, \boldsymbol{d} \boldsymbol{\varepsilon}^{b}$ and $\boldsymbol{a}$ are the stress, the plastic strain increment and the parameter describing the translation of loading surface respectively. And we set

$$
\hat{\boldsymbol{\sigma}}=\boldsymbol{\sigma}-\boldsymbol{\alpha}
$$

$f$ is a yield function to describe the yield condition, which is a function of $\hat{\boldsymbol{a}}$ and some parameters representing the effect of a history of plastic deforma- 
tion to the yield condition. $\mathrm{S}$ is a scalar function of stress and some internal variables. Assumption 1 can be regarded as the generalization of Prager's uniqueness condition for hardening materials $\left(\operatorname{tr}\left(d \boldsymbol{J} d \boldsymbol{\varepsilon}^{p}\right)>O\right)$.

Assumption 2 can be expressed as

$$
\operatorname{tr}\left(\frac{\partial f}{\partial \hat{\sigma}} d \sigma\right) \rightarrow 0 \text { as } d \varepsilon^{p} \rightarrow \mathbf{0}
$$

which is the inverse relation of Prager's continuity condition ( $d \boldsymbol{\varepsilon}^{p} \rightarrow \mathbf{0}$ as $\operatorname{tr}(\partial f)$ $\partial \boldsymbol{\sigma} d \boldsymbol{\sigma}) \rightarrow 0$ ) that does not hold in the loading state satisfying $\operatorname{tr}(\partial f / \partial \boldsymbol{\sigma} d \boldsymbol{\sigma})=0$. In addition to assumption 2, we assume that there exists a linear relation between $d \boldsymbol{\varepsilon}^{b}$ and $d a$. Thus it can be written that

$$
d \boldsymbol{\varepsilon}^{b}=\operatorname{tr}\left(\frac{\partial f}{\partial \hat{\boldsymbol{\sigma}}} d \boldsymbol{\sigma}\right) Q(\boldsymbol{Q} \neq \mathbf{0}),
$$

where the second-order tensor $\mathrm{Q}$ is a function of stress and some internal variables. The relation (8) means that the direction of plastic strain increment is independent of the stress increment.

Substitution of (8) into (5) leads to

$$
\operatorname{tr}(\boldsymbol{Q d \sigma})=S(>0) .
$$

Then, noting that the stress increment can have any direction, it must hold that

$$
Q=G \frac{\partial f}{\partial \sigma}
$$

with the condition

$$
G \operatorname{tr}\left(\frac{\partial f}{\partial \sigma} d \sigma\right)>0
$$

where $G$ is a scalar function of stress and some internal variables. Thus, the plastic strain increment is given from (8)-(11) as follows:

$$
d \boldsymbol{\varepsilon}^{p}=d \lambda \frac{\partial f}{\partial \sigma},
$$

where

$$
d \lambda \equiv \operatorname{Gr}\left(\frac{f}{\sigma} d \sigma\right)(>0)
$$

The equation (12) is to be the associated flow rule, while the restriction for $d \lambda$ to take the form (13) is imposed by assumption 2 and the linearity of the constitutive equation. Here, note that the convexity of the loading surface is not imposed in this approach. 


\section{DISCUSSION}

In this paper the associated flow rule which is the most fundamental rule in the traditional theory of plasticity was analytically derived on the basis of assumptions 1 and 2 . The above approach leads to the fact that this rule is applicable to the elastoplastic continuum with the elastic-plastic transition and the hardening, the perfectly-plastic and the softening behaviors independently of the elastic response. It refers to a more general elastoplastic continuum than those assumed in the past approaches. Here, remind that it is based on two assumptions which are generalization of distinct characteristics of the plastic deformation in the uniaxial loading. While these assumptions seem physically plausible, still it would be desirable to verify rationalities of them by any other fundamental principles on the plastic deformation.

\section{ACKNOWLEDGEMENT}

The author wishes to express his sincere gratitude to Prof. H. Yamaguchi of the Tokyo Institute of Technology for his kind advice and many helpful discussions. The results reported here were obtained in the course of research supported by the Aid for Scientific Researches from the Ministry of Education of Japan under Grant 265140 in 1977 and 355220 in 1978-9 to the author.

\section{REFERENCES}

Dafaias, Y. F. and E. P. Popov 1975 A model of nonlinearly hardening materials for complex loading. Acta Mechanica, 21: 173-192

Drucker, D. C. 1951 A more fundamental approach to plastic stress-strain relations. Proc. 1st U. S. Nat. Congr. Appl.Mech., ASME, 1951: 487-491

Drucker, D. C. 1964 On the postulate of stability of material in the mechanics of continua. Journal de Mechanique, 3 : 235-249

Eisenberg, M. A. and A. Phillips 1971 A theory of plasticity with non-coincident yield and loading surfaces. Acta Mechanica, 11: 247-260

Green, A. E. and P. M. Naghdi 1965 A general theory of an elastic-plastic continuum. Arch. Ration. Mech. Anal., 18: 251-281

Hashiguchi. K. 1978 Plastic constitutive equations of granular materials. Proc.U.S.-Japan Seminar on Continuum Mechanical and Statistical Approaches in the Mechanics of Granular Materials, 1978 : 321-329

Hashiguchi. K. 1979a Constitutive equations of granular media with an anisotropic hardening. Proc 3rd Int. Conf. Numer. Methods in Geomech., 1979: 435-440

Hashiguchi. K. 1979b Constitutive equations of elastoplastic materials with elastic-plastic transition. J. Appl.Mech., Trans. ASME (in press)

Il'ushin, A. A. 1961 On the postulate of plasticity. J. Appl. Math. Mech.(Translation of Prikladnaya Mathematika i Mekhanika) , $25: 746-752$

Krieg, R. D. 1975 A practical two surafce plasticity theory. J.Appl.Mech., Trans. ASME., $97: 641-646$

Mróz,Z. 1967 On the description of anisotropic workhardening. J.Mech. Phys. Solids, 15: 163-175 
Naghdi, P. M. and J. A. Trapp 1975a Restriction on constitutive equations of finitely deformed elastic-plastic materials. Quar.J. Mech.Appl. Math., 28: 25-56

Naghdi, P. M. and J. A. Trapp $1975 \mathrm{~b}$ On the nature of normality of plastic strain and convexity of yield surface in plasticity. J.Appl.Mech., Trans. ASME, 97: 61-66

Palmer, A. C., G. Mair and D. C. Drucker 1967 Normality relations and convexity of yield surface for unstable materials or structual elements. J. Appl.Mech., Trans. ASME, $89:$ 464-470

Phillips, A. and R. L. Sierakowski 1965 On the concept of the yield surface. Acfa Mechanica, 1: 29-35

Prager, W. 1949 Recent development in mathematical theory of plasticity. J. Appl.Phys., 20: $235-241$ 